\title{
A study of feto-maternal outcome in cases of pre-labour rupture of membranes
}

\author{
Koothan U. T. ${ }^{*}$, Nina V. Kate ${ }^{1}$, Anuradha V. ${ }^{2}$ \\ ${ }^{1}$ Department of Obstetrics and Gynecology, ${ }^{2}$ Department of Neonatology, RGGW and CH, Puducherry, India
}

Received: 25 July 2017

Accepted: 22 August 2017

\section{*Correspondence:}

Dr. Koothan U. T.,

E-mail: kootha05@gmail.com

Copyright: (C) the author(s), publisher and licensee Medip Academy. This is an open-access article distributed under the terms of the Creative Commons Attribution Non-Commercial License, which permits unrestricted non-commercial use, distribution, and reproduction in any medium, provided the original work is properly cited.

\begin{abstract}
Background: Prelabour rupture of membranes is a common obstetric problem and the assessment of women with possible membrane rupture is a management issue faced in every day practice. The diagnosis and treatment of Prelabour rupture of membranes depends upon the facilities available. Unrecognized and inadequately treated conditions can lead to various maternal and neonatal complications.

Methods: The present prospective study was conducted on 200 pregnant women satisfying the inclusion criteria after getting consent for participation. Pregnant women between the gestational age of $28-40$ weeks who presented with Prelabour rupture of membranes to casualty were enrolled into the study.

Results: $76.5 \%$ of the study participants were between $37-40$ weeks of gestation and the remaining $23.5 \%$ belonged to the preterm population. Maternal morbidity was found to be $68 \%$ among the study participants with latency period more than 24 hrs. $37.5 \%$ of the neonates developed morbidity and the neonatal mortality was $2 \%$.

Conclusions: Prelabour rupture of membranes contributes significantly to maternal morbidity, neonatal morbidity and perinatal mortality.
\end{abstract}

Keywords: Maternal morbidity, Neonatal morbidity and mortality, Prelabour rupture of membranes

\section{INTRODUCTION}

Prelabour rupture of membranes (PROM) is spontaneous rupture of membranes before onset of labour; this is, therefore, defined in the absence of any obvious cervical changes or contractions consistent with established labour. Although there is no specific time frame, labour is expected to commence within 1 or 2 hrs after PROM, but according to Pernoll, PROM is considered to be prolonged if it occurs more than 24 hours before the onset of labour. ${ }^{1,2}$

Term PROM complicates approximately 5-10\% of pregnancies. Preterm PROM occurs in 3\% of pregnancies and is responsible for approximately one-third of all preterm births. There are many risk factors which are associated with PROM.
They include lower genital tract infection, increased intrauterine pressure as in twins, hydraminos, incompetent os, dietary habits, smoking, placental pathology, low socioeconomic status and others. At the same time PROM often occurs in the absence of any known risk factors. ${ }^{3}$

The management of PROM is controversial. Currently most authorities accept a plan of active management which includes prevention of infection, delay of delivery until foetal maturity is achieved, and active intervention by induction if labour is no longer preventable or if early infection is suspected. ${ }^{4}$

The fetal consequences of preterm delivery due to PROM are Respiratory distress syndrome, hypothermia, hypoglycaemia, jaundice, necrotizing enterocolitis, 
intraventricular haemorrhage, neurologic impairment, apnoea, retro lental fibroplasias, broncho pulmonary dysplasia, Patent ductus arteriosus, fetal limb contracture formation, pulmonary hypoplasia and neonatal sepsis. ${ }^{5}$ Maternal complications of PROM are chorioamnionitis, endometritis, puerperal pyrexia, abruptio placenta, wound infection and $\mathrm{PPH}^{6}$

\section{METHODS}

After admission, full history including duration of pregnancy, time and onset of rupture of membranes, past history of rupture of membranes, past obstetric history were taken. Rupture of the membranes was diagnosed by documenting draining of clear fluid on per speculum examination. During speculum examination high vaginal swab was collected for culture and sensitivity.

Obstetric examination was done to know the maturity of fetus in weeks, presentation and position of fetus, fetal heart sounds and to rule out any signs and symptoms of chorioamnionitis. All cases were subjected to detailed ultrasonographic assessment of gestational age, liquor and placental location.

A single course of betamethasone consisting of two 12 mg I/M injection 24 hourly was given to all PROM patients after admission. In patients having uterine contractions short term tocolysis was given in order to allow steroid therapy which can produce maximal effect on pulmonary maturation. Fetal surveillance was by cardiotocography, auscultation of fetal heart sounds and daily fetal kick count chart. All patients received prophylactic antibiotic for 5 days after admission. The antibiotic was continued or changed depending upon the culture sensitivity report.

Maternal monitoring to detect the signs of chorioamnionitis was done by recording the pulse, blood pressure, temperature, abdominal tenderness, color and smell of liquor. All patients were observed for spontaneous onset of labour. Induction was advocated as per hospital protocol considering the gestational age, cervical condition, latent period, presentation of the fetus, symptoms and signs of infection.

The mother was observed carefully during her postnatal hospital stay, with special emphasis on temperature, pulse, lochia and involution. Condition of the baby during its hospital stay was observed carefully. Neonatal outcomes were categorised into: Healthy, presence of respiratory distress syndrome, early neonatal sepsis, days at neonatal Intensive Care Unit and neonatal death.

\section{Statistical analysis}

The data obtained from the study was analysed using IBM SPSS Version 22.0 software. Means and proportions were calculated for continuous variables and categorical variables respectively. Chi square test was used for finding statistically significant difference in proportions. Pearson correlation coefficient was estimated for finding linear association between two variables. $\mathrm{P}$ value $<0.05$ was considered to be statistically significant. Data entry was done using MS Excel 2013.

\section{RESULTS}

$76.5 \%$ of the study participants were at term gestation (37-40) weeks at the time of presentation and $3 \%$ of the participants were in the gestation age group of (28-32) weeks (Figure 1).

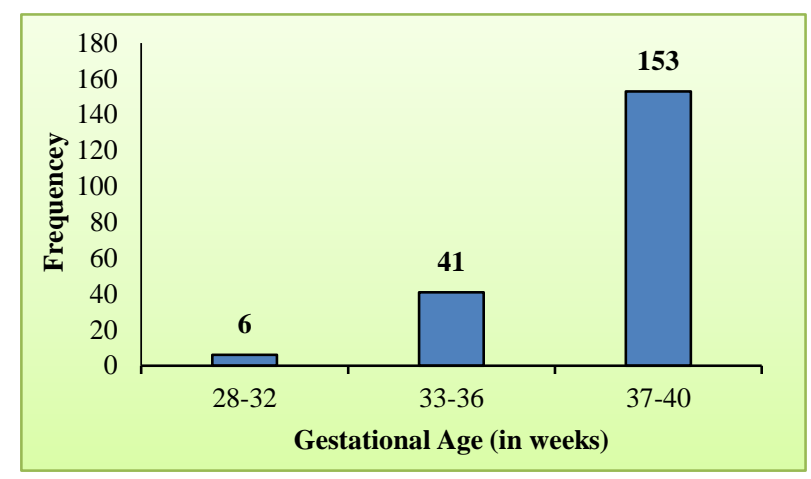

Figure 1: Distribution of study participants based on gestational age $(n=200)$.

Duration after rupture of membranes to delivery was less than 24 hours for $87.5 \%$ of the study participants, and within 12 hours for $44 \%$ of them while $12.5 \%$ of study participants delivered 24 hours after rupture of membranes (Figure 2).

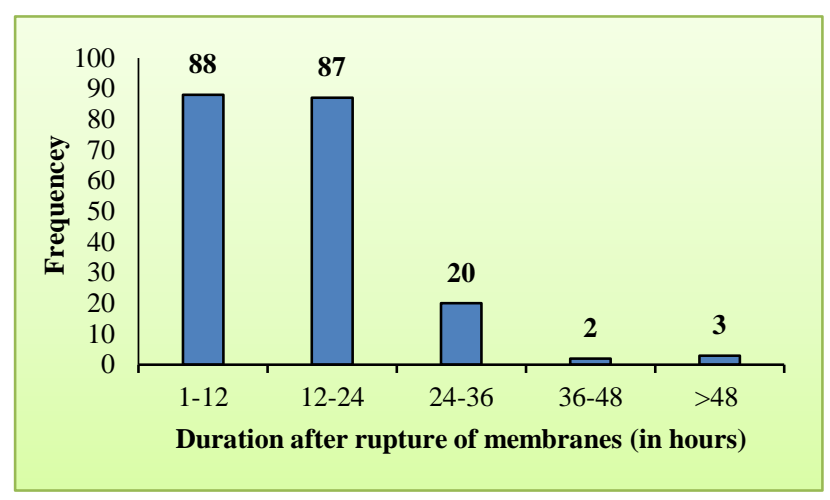

Figure 2: Distribution of study participants based on duration after rupture of membranes to delivery $(\mathbf{n}=\mathbf{2 0 0})$.

On Culture and sensitivity testing of high vaginal swab, $85.5 \%$ of the participants had no isolates or normal vaginal flora, while among $8.5 \%$ of the participants Candida Species was isolated followed by isolation of Klebsiella Species in $3.5 \%$ of study participants.

Staphylococcus was isolated in $2 \%$ of the study participants (Figure 3). 


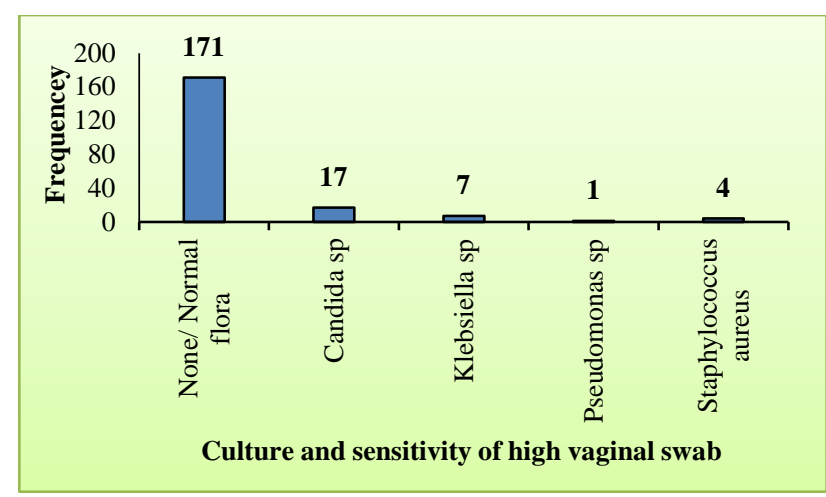

Figure 3: Distribution of study participants based on culture and sensitivity of high vaginal swab $(n=200)$.

$69.3 \%$ of the study participants at term gestation had SVD but there was no statistically significant association between gestational age and mode of delivery ( $\mathrm{p}$ value $=0.235)($ Table 1).

Table 1: Association between gestational age and mode of delivery $(n=200)$.

\begin{tabular}{|c|c|c|c|c|}
\hline \multirow{2}{*}{$\begin{array}{l}\text { Gestational } \\
\text { age (in } \\
\text { weeks) }\end{array}$} & \multicolumn{2}{|c|}{ Mode of delivery } & \multirow[b]{2}{*}{$\begin{array}{l}\text { Total } \\
\text { n (\%) }\end{array}$} & \multirow[b]{2}{*}{$\begin{array}{l}\text { p } \\
\text { value* }\end{array}$} \\
\hline & $\begin{array}{l}\text { LSCS } \\
\text { n }(\%)\end{array}$ & $\begin{array}{l}\text { SVD } \\
\text { n }(\%)\end{array}$ & & \\
\hline $29-32$ & $\begin{array}{l}0 \\
(0.0)\end{array}$ & $\begin{array}{l}6 \\
(100.0)\end{array}$ & $\begin{array}{l}6 \\
(100.0)\end{array}$ & \multirow{3}{*}{0.235} \\
\hline $33-36$ & $\begin{array}{l}14 \\
(34.1)\end{array}$ & $\begin{array}{l}27 \\
(65.9)\end{array}$ & $\begin{array}{l}41 \\
(100.0)\end{array}$ & \\
\hline $37-40$ & $\begin{array}{l}47 \\
(30.7)\end{array}$ & $\begin{array}{l}106 \\
(69.3)\end{array}$ & $\begin{array}{l}153 \\
(100.0)\end{array}$ & \\
\hline Total & $\begin{array}{l}61 \\
(30.5)\end{array}$ & $\begin{array}{l}139 \\
(69.5)\end{array}$ & $\begin{array}{l}200 \\
(100.0)\end{array}$ & \\
\hline
\end{tabular}

*Chi square test was applied

$83.6 \%$ of the study participants did not have any associated morbidity, where as $16.4 \%$ had various co morbidities of which fever accounted for $10.4 \%$ (Figure 4).

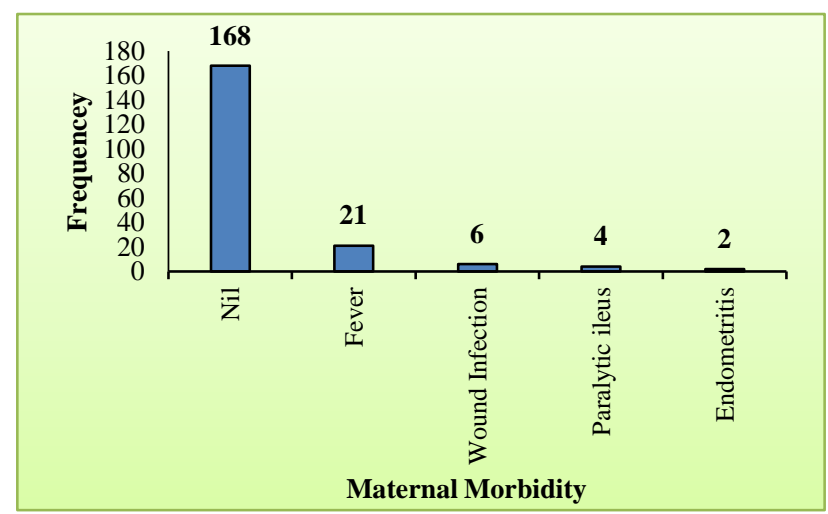

Figure 4: Distribution of study participants based on maternal morbidity $(n=200)$.

Respiratory Distress Syndrome (RDS) was observed to be present on $36.5 \%$ of the neonates involved in the study
(Figure 5) and Neonatal mortality was observed in $2 \%$ of the neonates of the study participants.

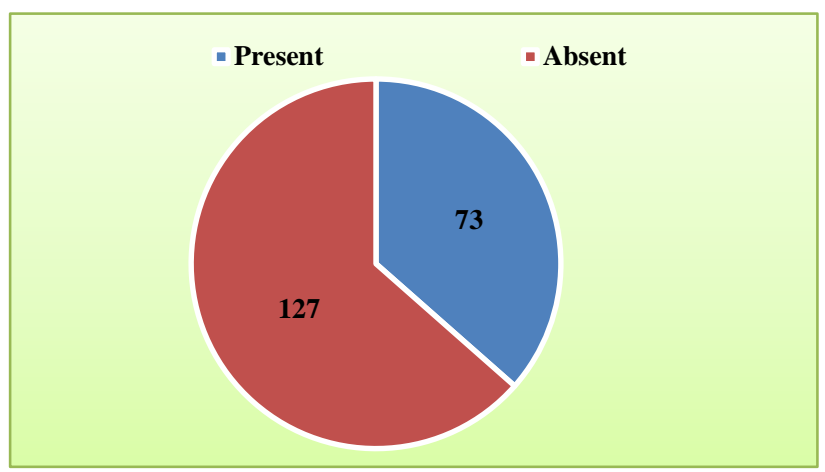

Figure 5: Distribution of neonates based on presence of $\operatorname{RDS}(n=200)$.

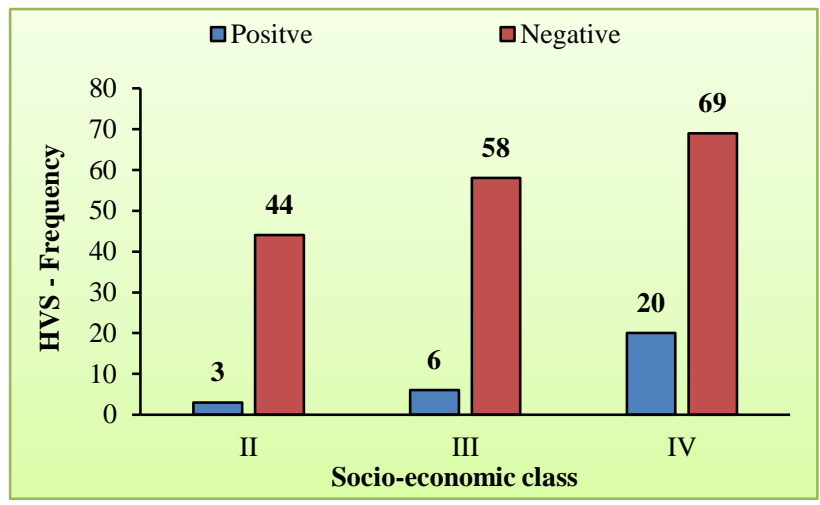

Figure 6: Association between socio-economic status and high vaginal swab culture results $(n=200)$.

$22.5 \%$ of study participants in socio-economic class IV were found to have positive High vaginal swab culture reports when compared to other classes. Also, this difference was found to be statistically significant ( $p$ value -0.015) (Figure 6).

Table 2: Association between amniotic fluid index and urine culture results $(n=200)$.

\begin{tabular}{|c|c|c|c|c|}
\hline \multirow{2}{*}{$\begin{array}{l}\text { Amniotic } \\
\text { Fluid } \\
\text { Index }\end{array}$} & \multicolumn{2}{|c|}{ Urine Culture } & \multirow{2}{*}{$\begin{array}{l}\text { Total } \\
\text { n (\%) }\end{array}$} & \multirow{2}{*}{$\begin{array}{l}\text { p } \\
\text { value* }\end{array}$} \\
\hline & $\begin{array}{c}\text { Positive } \\
\text { n (\%) }\end{array}$ & $\begin{array}{l}\text { Negative } \\
\text { n }(\%)\end{array}$ & & \\
\hline$<5$ & $14(45.2)$ & $17(54.8)$ & $31(100.0)$ & \multirow[t]{4}{*}{$<0.001$} \\
\hline $5-10$ & $9(13.4)$ & $58(86.6)$ & $67(100.0)$ & \\
\hline$>10$ & $8(7.8)$ & $94(92.2)$ & $102(100.0)$ & \\
\hline Total & $31(15.5)$ & $169(84.5$ & $200(100.0)$ & \\
\hline
\end{tabular}

$45.2 \%$ of study participants with lower amniotic fluid index were found to have positive urine culture reports when compared to adequate AFI (7.8\%).

Also, this association was found to be statistically significant ( $p$ value $-<0.001$ ). $19.4 \%$ of the study participants with lower amniotic fluid index were found 
to have positive high vaginal swab culture reports when compared to the participants with adequate amniotic fluid index $(7.8 \%)$.

Table 3: Association between amniotic fluid index status and high vaginal swab culture results $(n=200)$.

\begin{tabular}{|c|c|c|c|c|}
\hline \multirow{2}{*}{$\begin{array}{l}\text { Amniotic } \\
\text { fluid } \\
\text { index }\end{array}$} & \multicolumn{2}{|c|}{$\begin{array}{l}\text { High vaginal swab } \\
\text { culture }\end{array}$} & \multirow{2}{*}{$\begin{array}{l}\text { Total } \\
\text { n }(\%)\end{array}$} & \multirow{2}{*}{$\begin{array}{l}\text { p } \\
\text { value* }\end{array}$} \\
\hline & $\begin{array}{l}\text { Positive } \\
(\%)\end{array}$ & $\begin{array}{l}\text { Negative } \\
n(\%)\end{array}$ & & \\
\hline$<5$ & $6(19.4)$ & $25(80.6)$ & $31(100.0)$ & \multirow{4}{*}{0.022} \\
\hline $5-10$ & $15(22.4)$ & $52(77.6)$ & $67(100.0)$ & \\
\hline$>10$ & $8(7.8)$ & $94(92.2)$ & $102(100.0)$ & \\
\hline Total & $29(14.5)$ & $171(85.5)$ & $200(100.0)$ & \\
\hline
\end{tabular}

Also, this association was found to be statistically significant ( $\mathrm{p}$ value -0.022 ) (Table 2 and Table 3 ).

Table 4: Association between amniotic fluid index status and RDS in neonates $(n=200)$.

\begin{tabular}{|lllll|}
$\begin{array}{llll}\text { Amniotic } \\
\text { fluid } \\
\text { index }\end{array}$ & $\begin{array}{l}\text { RDS } \\
\text { Present } \\
\text { n(\%) }\end{array}$ & $\begin{array}{l}\text { Absent } \\
\text { n(\%) }\end{array}$ & $\begin{array}{l}\text { Total } \\
\text { n (\%) }\end{array}$ & $\begin{array}{l}\text { p } \\
\text { value* }\end{array}$ \\
\hline$<5$ & $18(58.1)$ & $13(41.9)$ & $31(100.0)$ & \\
\hline $5-10$ & $26(38.8)$ & $41(61.2)$ & $67(100.0)$ & 0.01 \\
\hline$>10$ & $29(28.4)$ & $73(71.6)$ & $102(100.0)$ & \\
\hline Total & $73(36.5)$ & $127(63.5)$ & $200(100.0)$ & \\
\hline
\end{tabular}

*Chi square test was applied

$58.1 \%$ of the study participants with amniotic fluid index less than five were found to have neonates with RDS when compared to the participants with amniotic fluid index more than five and this association was found to be statistically significant (p value - 0.01) (Table 4).

Table 5: Association between duration of rupture of membranes to delivery and maternal morbidity $(\mathbf{n}=$ 200).

\begin{tabular}{|c|c|c|c|c|}
\hline \multirow{2}{*}{$\begin{array}{l}\text { Duration of } \\
\text { rupture of } \\
\text { membranes } \\
\text { to delivery } \\
\text { (in hours) }\end{array}$} & \multicolumn{2}{|c|}{ Maternal morbidity } & \multirow[b]{2}{*}{$\begin{array}{l}\text { Total } \\
\text { n (\%) }\end{array}$} & \multirow[b]{2}{*}{$\begin{array}{l}\text { p } \\
\text { value* }\end{array}$} \\
\hline & $\begin{array}{l}\text { Present } \\
\text { n }(\%)\end{array}$ & $\begin{array}{c}\text { Absent } \\
\text { n (\%) }\end{array}$ & & \\
\hline$<12$ & $4(4.5)$ & $84(95.5)$ & $88(100.0)$ & \multirow{5}{*}{$<0.001$} \\
\hline $12-24$ & $12(13.8)$ & $75(86.2)$ & $87(100.0)$ & \\
\hline $24-36$ & $14(70.0)$ & $6(30.0)$ & $20(100.0)$ & \\
\hline $36-48$ & $1(50.0)$ & $1(50.0)$ & $2(100.0)$ & \\
\hline$>48$ & $2(66.7)$ & $1(33.3)$ & $3(100.0)$ & \\
\hline Total & $33(16.5)$ & $167(83.5)$ & $200(100.0)$ & \\
\hline
\end{tabular}

Morbidity was seen in $68 \%$ of the study participants with latency period more than 24 hrs which was statistically significant (p value -0.001) (Table 5).

$80 \%$ of the neonates born to mothers with latency period more than 24 hours were admitted in NICU which was found to be statistically significant ( $\mathrm{p}$ value $<0.001$ ) (Table 6).

Table 6: Association between duration of rupture of membranes to delivery and admission of neonate in NICU $(n=200)$.

\begin{tabular}{|c|c|c|c|c|}
\hline \multirow{2}{*}{$\begin{array}{l}\text { Duration of } \\
\text { rupture of } \\
\text { membranes } \\
\text { to delivery } \\
\text { (in hours) }\end{array}$} & \multicolumn{2}{|c|}{$\begin{array}{l}\text { Neonate admitted } \\
\text { in NICU }\end{array}$} & \multirow{2}{*}{$\begin{array}{l}\text { Total } \\
\text { n }(\%)\end{array}$} & \multirow{2}{*}{$\begin{array}{l}\text { p } \\
\text { value* }\end{array}$} \\
\hline & $\begin{array}{l}\text { Yes } \\
\text { n }(\%)\end{array}$ & $\begin{array}{l}\text { No } \\
\text { n }(\%)\end{array}$ & & \\
\hline$<12$ & $21(23.9)$ & $67(76.1)$ & $88(100.0)$ & \multirow{6}{*}{$<0.001$} \\
\hline $12-24$ & $34(39.1)$ & $5(60.9)$ & $87(100.0)$ & \\
\hline $24-36$ & $15(75.0)$ & $5(25.0)$ & $20(100.0)$ & \\
\hline $36-48$ & $2(100.0)$ & $0(0.0)$ & $2(100.0)$ & \\
\hline$>48$ & $3(100.0)$ & $0(0.0)$ & $3(100.0)$ & \\
\hline Total & $75(37.5)$ & $125(62.5)$ & $200(100.0)$ & \\
\hline
\end{tabular}

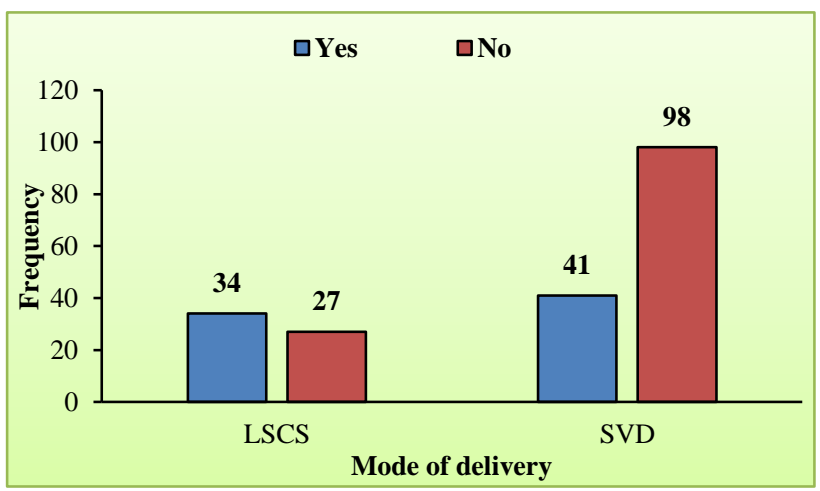

Among the study participants who had LSCS, $55.7 \%$ of the neonates were admitted in NICU as compared to SVD and this association was found to be statistically significant ( $\mathrm{p}$ value $<0.001$ ) (Figure 7).

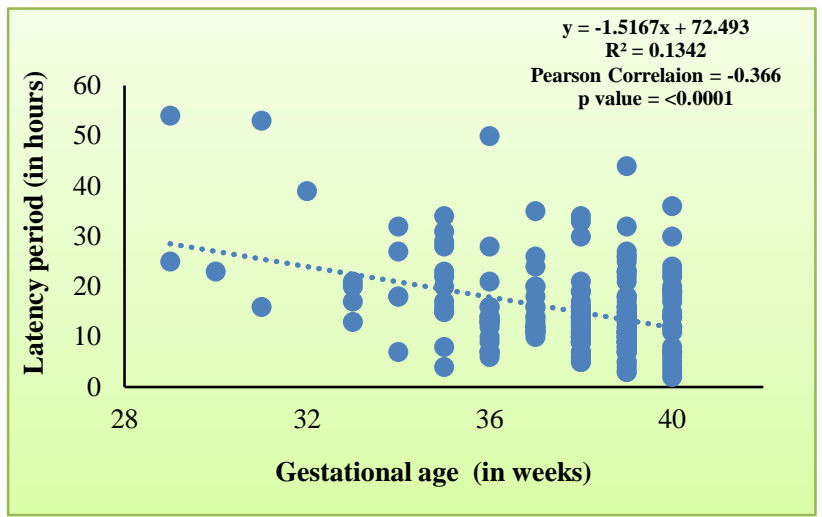

Figure 8: Correlation between duration of rupture of membranes to delivery and gestational age $(n=200)$.

A statistically significant inversely proportional relationship was observed between gestational age and latency period (p value<0.001) (Figure 8).

$74.4 \%$ of neonates of the study participants with preterm gestation were found to have Respiratory Distress 
Syndrome which was statistically significant ( $\mathrm{p}$ value $<0.001)$ (Table 7).

Table 7: Association between gestational age and presence of RDS in neonate $(n=200)$.

\begin{tabular}{|c|c|c|c|c|}
\hline \multirow{2}{*}{$\begin{array}{l}\text { Gestational } \\
\text { age (in } \\
\text { weeks) }\end{array}$} & \multicolumn{2}{|l|}{ RDS } & \multirow[b]{2}{*}{$\begin{array}{l}\text { Total } \\
\text { n }(\%)\end{array}$} & \multirow[b]{2}{*}{$\begin{array}{l}\text { p } \\
\text { value* }\end{array}$} \\
\hline & $\begin{array}{l}\text { Present } \\
\text { n }(\%)\end{array}$ & $\begin{array}{l}\text { Absent } \\
\text { n (\%) }\end{array}$ & & \\
\hline $29-32$ & $6(100.0)$ & $0(0.0)$ & $6(100.0)$ & \multirow{4}{*}{$<0.001$} \\
\hline $33-36$ & $29(70.7)$ & $12(29.3)$ & $41(100.0)$ & \\
\hline $37-40$ & $38(24.8)$ & $115(75.2)$ & $153(100.0)$ & \\
\hline Total & $73(36.5)$ & $127(63.5)$ & $200(100.0)$ & \\
\hline
\end{tabular}

$63.3 \%$ of the neonates with birth weight less than $2.5 \mathrm{~kg}$ were found to have Respiratory Distress Syndrome and was statistically significant (p value <0.001) (Table 8).

Table 8: Association between birth weight and presence of RDS in neonate $(n=200)$.

\begin{tabular}{|c|c|c|c|c|}
\hline \multirow{2}{*}{$\begin{array}{l}\text { Birth } \\
\text { Weight } \\
\text { (in Kg) }\end{array}$} & \multicolumn{2}{|l|}{ RDS } & \multirow[b]{2}{*}{$\begin{array}{l}\text { Total } \\
\text { n }(\%)\end{array}$} & \multirow{2}{*}{$\begin{array}{l}\text { p } \\
\text { value* }\end{array}$} \\
\hline & $\begin{array}{l}\text { Present } \\
\text { n }(\%)\end{array}$ & $\begin{array}{l}\text { Absent } \\
\text { n (\%) }\end{array}$ & & \\
\hline$<2.0$ & $12(100.0)$ & $0(0.0)$ & $12(100.0)$ & \multirow{4}{*}{$<0.001$} \\
\hline $2.0-2.5$ & $19(51.4)$ & $18(48.6)$ & $37(100.0)$ & \\
\hline $2.5-3.0$ & $28(29.5)$ & $67(70.5)$ & $95(100.0)$ & \\
\hline $3.0-4.0$ & $14(25.0)$ & $42(75.0)$ & $56(100.0)$ & \\
\hline Total & $73(36.5)$ & $127(63.5)$ & $200(100.0)$ & \\
\hline
\end{tabular}

\section{DISCUSSION}

The present study was carried out as a descriptive cross sectional study among 200 women with prelabour rupture of membranes (PROM) from August 2015 to July 2016 in the department of obstetrics and gynecology at Rajiv Gandhi Government Women and Children Hospital, Puducherry with an aim to identify the risk factors causing prelabour rupture of membranes and to study the labour outcome, maternal morbidity, perinatal morbidity and mortality associated with prelabour rupture of membranes (PROM).

Patients belonging to all age groups were in this study as no age is immune to PROM. In the present study $44.5 \%$ of study population belonged to the age group $21-25$ years. In a study conducted by Gandhi $\mathrm{M}$ et al, $59.4 \%$ belonged to the same age group. ${ }^{7} 52.1 \%$ of the study population in the study done by Vishwakarma $\mathrm{K}$ et al belonged to the same age group. ${ }^{8}$ In a study done by Patil $\mathrm{S}$ et al, $49 \%$ belonged to age group 21-25 years. ${ }^{4}$

In the present study $76.5 \%$ of the patients belonged to term population and $23.5 \%$ belonged to preterm population between 28 to 36.6 weeks of gestation. In a study conducted by Gandhi $\mathrm{M}$ et al $88.5 \%$ belonged to term population and $11.5 \%$ belonged to preterm population while in a study conducted by Vishwakarma
$\mathrm{K}$ et al $82.1 \%$ belonged to term population and $17.6 \%$ to preterm population. ${ }^{7,8}$

Among 200 women, 139 (69.5\%) delivered by normal vaginal delivery and $61(30.5 \%)$ women delivered by caesarian section, fetal distress being the commonest indication followed by failed induction and severe oligohydraminos.

$87.5 \%$ of the study population in the present study delivered within $24 \mathrm{hrs}$ of rupture of membranes and the remaining $12.5 \%$ delivered after $24 \mathrm{hrs} .44 \%$ of the study participants with latency period more than $24 \mathrm{hrs}$ were delivered by LSCS but this was statistically insignificant. An inversely proportional relationship was observed between gestational age and latency period which found to be statistically significant. In a study conducted by Abdul $\mathrm{R}$ et al $65.5 \%$ of the study population delivered within 24 hours and $64 \%$ of the study population delivered within 24 hrs in a study conducted by Patil S et al. $^{4,9}$

In the present study $14.5 \%$ of the study population had lower genital tract infection. Candida was the most common organism isolated followed by Klebsiella and Staphylococcus aureus. In a study conducted by Mohokar SA et $\mathrm{al}^{10}, 23 \%$ of the study participants had lower genital tract infection, of which $E$ Coli was the commonest organism isolated. ${ }^{10}$ In a study conducted by Lalwani et al $22 \%$ of the patients had lower genital tract infection, E Coli being the commonest followed by Klebsiella and Staphylococcus aureus. ${ }^{11} 12 \%$ of the patients had lower genital tract infection in a study done by Akter $\mathrm{S}$ et al. ${ }^{12}$ In a study conducted by Revathi $\mathrm{V}$ et $\mathrm{al}^{13} 10 \%$ of the study population had lower genital infection.

In the present study $15.5 \%$ of the population had Amniotic Fluid Index less than five. $45.2 \%$ of the study participants with AFI less than five were found to have urinary tract infection which was statistically significant. Also $19.4 \%$ of the study participants with Amniotic Fluid Index less than five had lower genital tract infection which was statistically significant. In a study done by Mohokar SA et al 33\% of the patients were found to have oligohydraminos ie AFI less than five. ${ }^{10}$

In the present study $16.4 \%$ of the study population had some or the other type of morbidity. Puerperal pyrexia being the commonest accounted for $10.4 \%$ of the study participants followed by wound infection which was found to be $3 \%$. Morbidity was seen in $68 \%$ of the study participants with latency period more than $24 \mathrm{hrs}$ which was statistically significant.

In a study conducted by Mohokar SA et al the maternal morbidity was found to be $16 \%$, in that puerperal pyrexia accounted for $12 \%$ of the study participants. ${ }^{10} 21.5 \%$ of the patients had morbidity in a study done by Abdul et al, where $7 \%$ of the study participants had puerperal pyrexia. 
Nearly $15 \%$ of the patients had morbidity in a study done by Vishwakarma K et al. ${ }^{8,9}$

In the present study $24.5 \%$ of the neonates had low birth weight, of which $6 \%$ of the neonates had birth weight less than $2 \mathrm{~kg}$. In a study done by Gandhi M et al $7.55 \%$ of the neonates had birth weight less than $2 \mathrm{~kg} .^{7} 31 \%$ of the neonates were found to be less than $2 \mathrm{~kg}$ in a study done by Patil $\mathrm{S}$ et al. ${ }^{4}$ In a study conducted by Mohokar SA et al as much as $50 \%$ of the neonates had birth weight less than 2 kg. ${ }^{10}$

In the present study $37.5 \%$ of the neonates were found to have some or the other type of morbidity and were admitted in NICU. Among the study participants who had LSCS, $55.7 \%$ of the neonates got admitted in NICU as compared to normal vaginal delivery and was found to be statistically significant. $80 \%$ of the neonates born to mothers whose latency period was more than 24 hours were found to have some or the other type of morbidity which was statistically significant. In a study done by Mohokar SA et al neonatal morbidity was found to be nearly $33 \%$ where as in a study done by Abdul $\mathrm{R}$ et al neonatal morbidity was $24.5 \%$. 9,10 Neonatal morbidity was $13 \%$ as quoted by Gandhi $\mathrm{M}$ et al in their study. ${ }^{7}$

Among the neonatal morbidity, Respiratory Distress Syndrome (RDS) was found to be the commonest morbidity involving $36.5 \%$ of the neonates in the present study. $58.1 \%$ of the study population with Amniotic Fluid Index less than five were found to have neonates with Respiratory distress syndrome which was statistically significant. $74.4 \%$ of neonates of the study participants with preterm gestation were found to have Respiratory Distress Syndrome which was statistically significant. $63.3 \%$ of the neonates with birth weight less than $2.5 \mathrm{~kg}$ were found to have Respiratory Distress Syndrome and was statistically significant. In a study done by Patil S et al $26 \%$ of the neonates had Respiratory Distress Syndrome while $21 \%$ of the neonates had Respiratory Distress Syndrome in a study done by Mohokar SA et al. ${ }^{4,10}$

In a study done by Akter S et al $11.1 \%$ of the neonates had Respiratory Distress Syndrome. ${ }^{12} 3.5 \%$ of the neonates presented with neonatal sepsis in the present study. In a study done by Anjana D et al it was found that $11.5 \%$ of the neonates had neonatal sepsis where as $24 \%$ of the neonates had neonatal sepsis in a study conducted by Shreshtha SR et al. ${ }^{14,15}$

In the present study, neonatal mortality was $2 \%$ which was similar to a study conducted by Gandhi $\mathrm{M}$ et al where the neonatal mortality was found to be $2.86 \%$. In a study done by Abdul R et al neonatal mortality was found to be $13 \% .^{7,9}$ Neonatal mortality was $7 \%$ in a study done by Patil $\mathrm{S}$ et al which was slightly higher when compared to a study done by Revathi $\mathrm{V}$ et al where the neonatal mortality was found to be $5 \% .4,13$

\section{CONCLUSION}

Prelabour rupture of membranes contribute significantly to maternal morbidity, neonatal morbidity and perinatal mortality. PROM is significantly associated with low socioeconomic status, genitourinary tract infections, anaemia and history of PROM and preterm labour in the previous pregnancy. A statistically significant inversely proportional relationship was observed between gestational age and latency period. There is a strong correlation between latency period and maternal and neonatal morbidity and perinatal mortality. Also, neonatal morbidity and mortality were high in prematurity and low birth weight babies. Close antenatal monitoring, good hygine, nutritious diet, early identification of risk factors and health education can decrease the incidence of PROM. In managing PROM, timely use of proper antibiotics, steroids and induction or augmentation of labour, reduce the hospital stay and ultimately reduce neonatal and maternal complications.

Funding: No funding sources

Conflict of interest: None declared

Ethical approval: The study was approved by the Institutional Ethics Committee

\section{REFERENCES}

1. Theron GB. Preterm rupture of membranes. In: Cronje HS, Cilliers JBF, Pretorius MS. Clinical Obstetrics: a Southern African perspective. $3^{\text {rd }} \mathrm{Ed}$. Pretoria. Van Schaik;2011:204-10.

2. Pernoll ML. Untimely termination of pregnancy. In: Pernoll ML, Benson RC. Current Obstetric and Gynecologic Diagnosis and Treatment. 6th Ed. California: Appleton and Lange;1987:308-10.

3. Mercer BM. Is there a role for tocolytic therapy during conservative management of preterm premature rupture of the membranes? Clin Obstet Gynecol. 2007;50(2):487-96.

4. Patil S, Patil V. Maternal and foetal outcome in premature rupture of membranes. IOSR-JDMS. 2014;13(12):56-83.

5. Cunningham FG, Mac Donald PC, Gant NF, Leveno KJ, Gilstrap LC editors. Williams Obstetrics: Preterm labor, Prelabor ruptures of membranes. 19th edition. California, USA: Appleton and Lange; 1993:361.

6. Jones G. Prelabour rupture of the membrane. In Luesley D, Baker P, Drife J editors: Obstetrics and Gynaecology-An evidenced based text for MRCOG. London: Hodder Arnold;2004:297.

7. Gandhi M, Shah F, Panchal C. Obstretic outcome in premature rupture of membrane (prom). Internet Journal Gynecol Obstret. 2012;16(2).

8. Vishwakarma K, Patel SK, Yadav K, Pandey A. Impact of premature rupture of membranes on maternal neonatal Health Central India. J Evid based Med Healthc. 2015;2(49):8505 
9. Abdul R, Seema M, Singh BN. Maternal and foetal outcome in cases of pre-labour rupture of membranes.

10. Mohokar SA, Bava AK, Nandanwar YS. Analysis of maternal and perinatal outcome in cases of preterm premature rupture of membranes. Bombay Hospital J. 2015;57(3):285.

11. Lalwani A, Najam R. The Prospective study of the incidence, etiological factors and maternal outcome in pre-labour ruptured membranes (Term and Preterm). Annal Int Med Dental Res. 2016;2(2):122-5.

12. Akter S, Akter R, Rashid M. Preterm Prelabour rupture of the membrane and feto- maternal out come: an observational study. J Bangladesh Coll Physic Surg. 2010 Jan 1;28(1):17.
13. Revathi V, Sowjanya R, Lavanya S. Maternal and perinatal outcome in premature rupture of membranes at term. IOSR-JDMS. 2015:14(4);12-5.

14. Anjana D, Reddi R. Premature rupture of membranes: a clinical study. Obstet Gynecol. 1996;46:63-76.

15. Shrestha SR, Sharma P. Fetal outcome of pre-labor rupture of membranes. Nepal J Obstet Gynecol. 2015;1(2):19-24.

Cite this article as: Koothan UT, Kate NV, Anuradha V. A study of feto-maternal outcome in cases of pre-labour rupture of membranes. Int J Reprod Contracept Obstet Gynecol 2017;6:4473-9. 